\title{
Erratum to: Use of high-energy laser radiation for surface preparation of magnesium for adhesive applications
}

Norbert Schneider $^{1 *}$, Christian Wrobel ${ }^{2}$ and Jens Holtmannspötter ${ }^{3}$

${ }^{*}$ Correspondence:

norbert2schneider@

bundeswehr.org

${ }^{1}$ Wehrwissenschaftliches

Institut für Werk- und

Betriebsstoffe, Institutsweg 1,

85435 Erding, Germany

Full list of author information

is available at the end of the

article

\section{Erratum to: Appl Adhes Sci (2015) 3:17 \\ DOI 10.1186/s40563-015-0044-2}

The original version of this article [1] was published with an incomplete author list. Author Jens Holtmannspötter has been added with the publication of this Erratum.

\section{Author details}

${ }^{1}$ Wehrwissenschaftliches Institut für Werk- und Betriebsstoffe, Institutsweg 1,85435 Erding, Germany. ${ }^{2}$ Bundeswehr Universität, Werner-Heisenberg-Weg 39, 85577 Neubiberg, Germany. ${ }^{3}$ Bundeswehr Research Institute for Materials, Fuels and Lubricants (WIWeB), Institutsweg 1, 85435 Erding, Germany.

Published online: 10 February 2016

The online version of the original article can be found under doi:10.1186/s40563-015-0044-2.

\section{Reference}

1. Schneider N, Wrobel C, Holtmannspötter J. Use of high-energy laser radiation for surface preparation of magnesium for adhesive applications. Appl Adhes Sci. 2015;3:17. 